\title{
Towards sustainable partnerships in global health: the case of the CRONICAS Centre of Excellence in Chronic Diseases in Peru
}

J. Jaime Miranda ${ }^{1,2 *}$, Antonio Bernabé-Ortiz ${ }^{1,3}$, Francisco Diez-Canseco ${ }^{1}$, Germán Málaga ${ }^{1,2,4}$, María K. Cárdenas ${ }^{1}$, Rodrigo M. Carrillo-Larco ${ }^{1,2}$, María Lazo-Porras ${ }^{1}$, Miguel Moscoso-Porras ${ }^{1}$, M. Amalia Pesantes ${ }^{1}$, Vilarmina Ponce ${ }^{1}$, Ricardo Araya ${ }^{5}$, David Beran ${ }^{6,7}$, Peter Busse ${ }^{8}$, Oscar Boggio ${ }^{9}$, William Checkley ${ }^{10,11}$, Patricia J. García ${ }^{3}$, Luis Huicho 2,12,13, Fabiola León-Velarde ${ }^{14}$, Andrés G. Lescano ${ }^{3,15}$, David C. Mohr ${ }^{16}$, William Pan ${ }^{17}$, David Peiris ${ }^{18}$, Pablo Perel ${ }^{5,19}$, Cristina Rabadán-Diehl ${ }^{20}$, Maria Rivera-Chira ${ }^{14}$, Katherine Sacksteder ${ }^{11}$, Liam Smeeth ${ }^{5}$, Antonio J. Trujillo ${ }^{11}$, Jonathan C. K. Wells ${ }^{21}$, Lijing L. Yan ${ }^{22}$, Héctor H. García ${ }^{13,23,24}$ and Robert H. Gilman 10,25

\begin{abstract}
Human capital requires opportunities to develop and capacity to overcome challenges, together with an enabling environment that fosters critical and disruptive innovation. Exploring such features is necessary to establish the foundation of solid long-term partnerships. In this paper we describe the experience of the CRONICAS Centre of Excellence in Chronic Diseases, based at Universidad Peruana Cayetano Heredia in Lima, Peru, as a case study for fostering meaningful and sustainable partnerships for international collaborative research. The CRONICAS Centre of Excellence in Chronic Diseases was established in 2009 with the following Mission: "We support the development of young researchers and collaboration with national and international institutions. Our motivation is to improve population's health through high quality research." The Centre's identity is embedded in its core values generosity, innovation, integrity, and quality - and its trajectory is a result of various interactions between multiple individuals, collaborators, teams, and institutions, which together with the challenges confronted, enables us to make an objective assessment of the partnership we would like to pursue, nurture and support. We do not intend to provide a single example of a successful partnership, but in contrast, to highlight what can be translated into opportunities to be faced by research groups based in low- and middle-income countries, and how these encounters can provide a strong platform for fruitful and sustainable partnerships. In defiant contexts, partnerships require to be nurtured and sustained. Acknowledging that all partnerships are not and should not be the same, we also need to learn from the evolution of such relationships, its key successes, hurdles and failures to contribute to the promotion of a culture of global solidarity where mutual goals, mutual gains, as well as mutual responsibilities are the norm. In so doing, we will all contribute to instil a new culture where expectations, roles and interactions among individuals and their teams are horizontal, the true nature of partnerships.
\end{abstract}

Keywords: Partnerships, Low- and middle-income countries, Team management, Capacity building, Training

\footnotetext{
* Correspondence: jaime.miranda@upch.pe

${ }^{1}$ CRONICAS Centre of Excellence in Chronic Diseases, Universidad Peruana

Cayetano Heredia, Av. Armendáriz 497, Miraflores, Lima 18, Peru

${ }^{2}$ School of Medicine, Universidad Peruana Cayetano Heredia, Lima, Peru

Full list of author information is available at the end of the article
} 


\begin{abstract}
Spanish)
Además de la necesidad de contar con un ambiente proactivo que impulse la innovación crítica y disruptiva, el capital humano requiere tanto de oportunidades para su desarrollo como de capacidades para asumir y sobreponerse a retos. Explorar dichas características permitirá establecer las bases para asociaciones (en Inglés partnerships) sólidas y duraderas. En este artículo se describe la experiencia de CRONICAS Centro de Excelencia en Enfermedades Crónicas de la Universidad Peruana Cayetano Heredia en Lima, Perú, como un caso de promoción de asociaciones valiosas y sostenibles para el desarrollo de investigaciones colaborativas a nivel internacional. La Misión de CRONICAS Centro de Excelencia en Enfermedades Crónicas, establecido en el año 2009, indica que "Apostamos por la formación de jóvenes investigadores y la colaboración con instituciones locales e internacionales. Nuestra motivación es mejorar la salud de la población a través de investigación de alta calidad". La identidad del Centro se refleja en sus valores, — generosidad, innovación, integridad y calidad — y la trayectoria del mismo es el reflejo de múltiples interacciones entre individuos, colaboradores, equipos e instituciones. Sumadas a los retos afrontados, este recorrido se traduce en experiencias concretas que alimentan una evaluación objetiva apuntando a definir un perfil o tipo de asociaciones que ameritan alimentarse y protegerse. No se pretende brindar ejemplos de un perfil particular de asociación exitosa, sino, al contrario, resaltar y transmitir potenciales oportunidades para otros grupos de investigación también ubicados en países de ingresos bajos y medios, y cómo dichas experiencias pueden proveer de una amplia plataforma que permita la generación de asociaciones fructíferas y sostenibles. En contextos con limitaciones y retos cotidianos, las asociaciones requieren ser amamantadas, cuidadas y sostenidas. El reconocer que las distintas asociaciones no son ni deberían ser idénticas entre ellas nos permite aprender de la evolución de las mismas, de sus éxitos y sus obstáculos, así como de sus fallas. Esto se traduciría ulteriormente en la promoción de una cultura de solidaridad global en donde los objetivos comunes junto con los beneficios comunes, de la mano de las responsabilidades comunes, sean la norma. De esta manera, todas las partes y actores involucrados contribuyen a instilar una nueva cultura de horizontalidad a nivel de expectativas, roles e interacciones entre individuos y sus equipos, es decir la verdadera naturaleza de un partnership.
\end{abstract}

\section{Background}

The global challenge of non-communicable diseases requires local and international actors working together and effectively to accomplish major achievements, likely of mutual benefit, for example poverty reduction $[1,2]$. The World Health Organization's Global Action Plan [3] states the importance of promoting and supporting national capacity for high-quality research and for developing prevention and control strategies.

The CRONICAS Centre of Excellence in Chronic Diseases, established at Universidad Peruana Cayetano Heredia in Peru, has achieved a substantial track record in securing internationally competitive research grant support [4], being a key actor in major awarded projects totalling approximately $\sim$ USD $\$ 17.5$ million dollars. Whilst research funding can be a powerful indicator, it is an incomplete marker of capacity building. It conceals significant investments and achievements in terms of another major success factor: trained, engaged and committed human capital and talent. The CRONICAS Centre of Excellence in Chronic Diseases was established in 2009 with the following Mission: "We support the development of young researchers and collaboration with national and international institutions. Our motivation is to improve population's health through high quality research." The Centre's identity is embedded in its core values - generosity, innovation, integrity, and qualityand a list of ongoing projects is available at http:// en.cronicas-upch.pe/proyectos/.

Research does not happen in isolation. For talent to strive, it is important to leverage existing research platforms and institutional support $[4,5]$. Furthermore, research needs partnerships beyond specific scientific topics or projects, partnerships that foster and develop capacity building. As with any organisation, human capital requires opportunities to develop and capacity to overcome challenges. It also needs an enabling environment fostering critical and disruptive innovation [6]; one where working in partnerships is embedded in day-today interactions. In this regard, much of the success of the CRONICAS Centre of Excellence is largely due to the nurturing environment or ecosystem of its host institution, the Universidad Peruana Cayetano Heredia, one that is largely prone to support scientific research [7-10] alongside with global health training and collaboration $[11,12]$. This environment largely explains the leading track record of this institution in promoting science within Peru and the Latin American region [13]. In addition to this, the establishment of the CRONICAS Centre of Excellence in Chronic Diseases in Peru benefited from having a platform to leverage collaborations with other Centres of Excellence with different degrees 
of development and expertise, thus leapfrogging the chances to maximise opportunities for collaborative work $[5,14]$.

Partnership, especially partnerships in health, have been previously explored in terms of its 'success', showing that such conceptualization yields a strong predominance of evaluations of processes rather than outcomes of success per se [15]. Another entry point for the evaluation of partnerships has been through a framework that operationalizes partnership synergies [16]. In this paper we describe the experience of the CRONICAS Centre of Excellence as a case study for fostering meaningful and sustainable partnerships for international collaborative research under the umbrella of non-communicable diseases. The Centre's trajectory is a result of various interactions between multiple individuals, collaborators, teams, and institutions, which together with the challenges encountered, enables us to make an objective assessment of the partnership we would like to pursue, nurture and support.

We do not intend to provide a single example of a successful partnership, but in contrast, to highlight the many challenges and opportunities faced by research groups based in low- and middle-income countries, and how these encounters can provide a strong platform for fruitful and sustainable partnerships. Our Centre operates in a country that has recently been categorised as an upper-middle-income economy. Peru, however, with over a quarter of its population living on poverty [17], lacks behind in many major social indicators. For example, it has one of the lowest per capita health expenditures in the region $[18,19]$ and one of the lowest scores in quality of education [20]. This is a particularly defiant context, in great need for partnerships to be established, nurtured and sustained in order to secure a transition "from construction workers to architects" [21]. Acknowledging that all partnerships are not and should not be the same, we also need to learn from the evolution of such relationships, its key successes, hurdles and failures.

\section{Review}

\section{Principles for Partnerships}

Research projects are time-bound, having an end-date, and usually prioritize research objectives over the development of young researchers. Funding cycles and priorities are constantly changing, overarching interinstitutional agreements focus largely on institutions and less so on people, and funding availability for scientific research remains a constant concern. These factors are beyond the direct influence of many research teams, who need to find ways of managing such uncertain scenario.
From a pragmatic point of view, we contend that partnerships are key to protect and nurture our human capital, and to enhance our local talent [14, 21-25]. Yet, we are also aware that predominant approaches of partnerships, such as North-led, high-income country led, medical professional led, and its combinations, have to be constantly revisited.

Partnerships require several forms and degrees of interaction, communication, and mutuality, as stated by the Swiss Commission for Research Partnerships with Developing Countries (KFPE) [26, 27]. This approach has challenged our team to defend horizontality, mutuality, and willingness to accommodate to the interests of the majority, and to live by our Centre's values of generosity, innovation, integrity and quality.

The eleven principles recommended by the KFPE guide are 1) Set the agenda together, 2) Interact with stakeholders, 3) Clarify responsibilities, 4) Account to beneficiaries, 5) Promote mutual learning, 6) Enhance capacity, 7) Share data and networks, 8) Disseminate results, 9) Pool profits and merits, 10) Apply results, and 11) Secure outcomes. Some items from this list, specifically principles $1,3,5,6,7$, and 9 , call for a strong organizational culture, a culture where shared values between local and international partners should reign. The remaining set of principles also calls for a proactive responsibility with external actors.

Throughout this manuscript, we describe why and how such coherence is needed to sustain real long-term partnerships, such as the ones nurtured by CRONICAS and its international collaborators. Addressing partnerships in isolation would be irresponsible, and more concretely, we cannot address partnership without looking into capacity building efforts or directly stated "what is in it for us?"

\section{Capacity building}

Capacity building is a key aspect of our Centre's mission [4]. This is achieved through a number of initiatives both university-wide and within our own Centre including supported Fellowships, hands-on engagement of students through the different aspects of research, and the attraction of $\mathrm{PhD}$ graduates to lift up our local research capacity to train future researchers [4].

Institutions cannot stand alone, and they cannot succeed nor progress if it were not for its people. We need quality people, who can be trained and will become engaged professionals contributing towards the advancement of society whilst addressing local needs. Universidad Peruana Cayetano Heredia is the leading institution in scientific production in Peru [13], with the highest output of scientific publications and with an overall normalised impact above the world's average [13] as per international indicators [28]. Universidad Peruana 
Cayetano Heredia has trained health professionals in research for more than 50 years, and is constantly exploring and supporting alternative models of educational and research engagement $[4,29,30]$.

\section{Masters degree in epidemiological methods}

Postgraduate training is essential for creating and sustaining networks and partnerships for future research opportunities. The Masters' programme, organised by the Universidad Peruana Cayetano Heredia and the U.S. Naval Medical Research Unit No. 6 (NAMRU-6), provides extensive training in epidemiological methods training, coupled with hands-on experience in the preparation of a scientific publication as a mechanism for graduation. International researchers from the CRONICAS Centre of Excellence and many other groups in Peru rotate as faculty and mentors. Outstanding graduates are invited to join as teaching assistants and progress to becoming junior faculty, therefore expanding the base to train future generations.

\section{CRONICAS research fellowships}

Within Peru, our Centre of Excellence has pioneered the creation of a competitive Fellowship programme, the CRONICAS Scholarship, to support postgraduate training in the epidemiology of chronic diseases that includes full tuition support for a Masters in Epidemiological Research among other benefits.

The CRONICAS Fellowship is the first of its kind in Peru, and in only 5 years it has become extremely successful by multiple measurements. For example, we average 70 applicants per year for one Fellowship opportunity. The quality of our fellows is also very high: CRONICAS Fellows rank among the top Masters' students in all 5 years since our inception. Nineteen CRONICAS Fellowships have been awarded to individuals with backgrounds in economics, medicine, nutrition, physical therapy, psychology, and statistics. To date, after completion of the Masters' program, our Fellows have achieved different public health related positions, such as research project managers (4 fellows), chiefs of health departments' units (2 fellows), and teaching assistants in a Masters program (4 fellows).

This speaks to our successful outreach, but also often leads us in new and exciting research directions that we would not have explored without the input from these Fellows from a range of scientific disciplines. Long after completing their Masters' training, most of our former Fellows engage with our ongoing work: several graduates of the Masters' programme joined CRONICAS as adjunct scientists, thus enhancing the mentorship they receive together with augmenting their exposure to research opportunities.
Most recently in early 2015, CRONICAS conducted an evaluation of its Fellowship programme using two different avenues. First, previous Fellows were tasked to review the experience and trajectories of the scholarship beneficiaries. They found that most of the beneficiaries were recently graduated from careers related to health with strong interest in research. However, most of them were not able to find a collaborative group and/or opportunities to develop their research careers. As one of the CRONICAS Fellows stated: "It has been the best opportunity to enter into the world of scientific research with high international standards". Another Fellow described her experience at CRONICAS as: "Finding the ideal working group to develop myself as a researcher".

In an open public consultation, using social media channels, we asked our external audience if the CRONICAS Scholarship should continue or not. We received many requests from our followers. We highlight two comments that summarize the demand for continuity CRONICAS Scholarship: "This scholarship not only finances one of the best Masters' programs in research in Peru but also offers the opportunity to be in an environment where research is a everyday activity, and you get apply what you learn on a daily basis, in addition to establish links with senior researchers and gaining access to sources of data from which you can develop new studies." Another one added, "If one looks for researchoriented health institutions, there are very few of them. CRONICAS has set a good precedent to get more young people interested in research, its work should be continued and while this constitutes a major challenge ... there are those willing to face them."

\section{Hands-on engagement of students and young graduates}

Another route for engagement is through learning-bydoing. In CRONICAS we welcome trainees to join our team, ideally for at least 1 year. This will enable them to learn about the various stages of research through active involvement. For example, some trainees have worked on hypothesis-driven secondary analysis of available data [31-33], while others support our ongoing projects or research initiatives, participating in project management, grant writing and writing-up scientific manuscripts. In this way, early-stage trainees receive mentoring and advice upon which they will develop their future interests and capacities. Under this scheme, trainees and visitors have been extremely productive, producing more than 70 first-authored publications under the mentorship of CRONICAS investigators [34].

CRONICAS Fellows and trainees are encouraged and welcomed to actively participate in proposing new research projects and to lead on grant applications. They receive critical advice from senior investigators and key input from specialists to develop a strong research idea. 
They also receive active support throughout the grant writing process. For example, CRONICAS trainees were awarded three seed grants from the National Heart, Lung and Blood Institute supplementary grants available through the Centres of Excellence network under a competitive application process [14]. Our trainees have led successful bids winning awards totalling USD \$390,000 dollars to date.

\section{Promoting and attracting high-calibre postgraduates}

The repatriation scheme of $\mathrm{PhD}$ professionals promoted by Peruvian National Council for Science, Technology and Technological Innovation (CONCYTEC) was created in 2014 as a new opportunity and development pathway to enhance capacity building initiatives. Under this scheme, our Centre hosts a postdoctoral fellow trained in public health and medical anthropology. Additionally, one of our investigators has been awarded a Wellcome Trust Research Training Fellowship to pursue doctoral training in the UK, hence expanding the professional base of our Centre. Some of our trainees are further exploring other avenues for professional development thus expanding and nurturing the connection-base with other institutions. Two of our trainees are pursuing further career development opportunities in USA and UK. In the same vein, another one has been relocated to China for 2 months to work in specific research projects of mutual interest to both countries, therefore introducing a practical element of investing in sustaining the relationship between our research teams across the borders.

\section{Avoiding silo mentality}

Our focus on partnership believes in the advantages of linking diverse areas of expertise as means to move forward in conducting research. Hence, it is vital that every single team member from the CRONICAS Centre, from junior to senior levels, together with international collaborators, step out of their silos and work together to maximise the returns of innovative research [4]. In this section we briefly present some of these interdisciplinary interactions.

\section{Linking infectious disease and child health with non- communicable diseases}

To research on non-communicable diseases does not mean to avoid infectious diseases or other conditions. We have investigated the impact of child growth in a setting where diarrhoea is highly prevalent on blood pressure and obesity $[35,36]$. One of these studies showed that increased weight growth during infancy and early childhood was associated with decreased systolic blood pressure and central adiposity in adolescence, and the near $50 \%$ rate of chronic under-nutrition baseline
[37], may have impacted the observed associations between exposures and outcomes [38]. These findings may have not been found in other settings where the pattern of exposures and observed associations is completely different [39].

\section{Hypoxia and human adaptation to high altitude}

Moving beyond the physiological mechanisms underpinning high altitude hypoxia adaptive responses to include the role of other environmental factors is an area that has largely been neglected in the high altitude research agenda [40-42]. In Puno, a highland Peruvian area located at $3825 \mathrm{~m}$ above sea level, our international team of researchers showed that excessive erythrocytosis was strongly associated with having metabolic syndrome and being overweight, besides its association with hypoxemia and lower forced vital capacity [43]. Other high altitude research includes investigations of biomarkers linked to excessive erythrocytosis [44], use of point-of-care devices for screening of excessive erythrocytosis [45], and studies of the link between hypoxemia and cardiometabolic conditions [46].

\section{Evolutionary biology}

While diverse components of metabolism and body composition are implicated in the pathway to noncommunicable diseases, the development of such variability can also be considered as adaptation to local ecological conditions. The 'standard medical model' pays inadequate attention to the variability in normal ranges of traits that occur across populations. An evolutionary perspective can help understand the local manifestation of broader pathways to disease, with the ultimate aim of identifying new potential targets for public health interventions. For example, the association between infant weight gain and later body composition is not uniform between high- and low-/middle-income populations [47], hence the twin challenges of reducing undernutrition without exacerbating obesity risk must be resolved on a population-specific basis.

We conducted a study comparing growth and development between high altitude agropastoral communities (Vinchos and Santillana Districts of Ayacucho Region) and a low altitude urban community (Pampas de San Juan de Miraflores, Lima). We first showed that the shorter stature of the rural high altitude population was disproportionately in lower limb lengths, compared to hand/foot lengths, upper limb lengths or torso height [48]. This highlights how different components of growth are selectively sacrificed under ecological stress, while we also demonstrated that variability in arterial oxygen saturation is only one of the underlying mechanisms [49]. We further showed that short stature was associated with obesity risk in contrasting ways in these 
communities, such that stunting increased obesity risk in the rural high-altitude population, but decreased it in the urban low altitude population [50]. This suggests contrasting metabolic adaptations in association with growth, with implications for obesity prevention efforts. Finally, we also showed that Andean ancestry mediated the effect of altitude on the growth patterns [51].

In a separate study, we examined the impact on growth outcomes of a recent El Niño event, a climatic extreme to which Peru is regularly exposed. In the Tumbes region, we showed that being born at the time of the $1997 \mathrm{El} \mathrm{Niño}$ was associated with reduced height and lean mass in childhood, without any corresponding effect on fatness [52]. The same climate events also increase the prevalence of childhood diarrhoea [53]. Since height and lean mass are protective against diabetes, whereas body fat elevates risk, this stress may shape diabetes risk in adult life.

Collectively, these studies indicate that growth patterns are strongly shaped by both ancestry and ecological conditions, so that these factors shape the developmental pathway to chronic disease risk. An evolutionary approach aids interpret such data, and can help utilise the findings in public health efforts.

\section{Individual-environment ecosystems and human vulnerability}

One of our projects, combining team efforts between Brazil, Ecuador, Peru and USA, focuses on exploring the impact of anthropogenic land use/land cover and climate change on human and natural systems that affect the development of both infectious and non-communicable diseases in the Amazon. This initiative, supported by the Inter-American Institute for Global Change Research, brings together multidisciplinary experts to better understand socio-ecological vulnerability and resilience in rural tropical environments. The project is predicated on the idea that coupled land-climate change dynamics in the Amazon are primarily driven by human livelihood response, which refer to economic, environmental, and human health events that affect household risks. Managing this risk is a trade-off between the vulnerable state in which households exist and the resilience they have acquired to tolerate risk. This study will implement the same methodology and tools to collect data in Machadinho (Rondonia, Brazil), Madre de Dios (Peru), and the provinces of Succumbios and Orellana in the northern Ecuadorian Amazon to define a multi-dimensional metric of vulnerability and resilience that is sensitive to cultural, political, economic and demographic differences and directly applicable to current health threats.

Knowledge translation, advocacy and policy development Since its inception, our Centre has collaborated with the Ministry of Health's National Health Strategy for Non-
Communicable Diseases. In addition, our group has served different healthcare service providers and policyoriented bodies including the Congress of Peru, Pan American Health Organization's Advisory Committee for Health Research, Peruvian Diabetes Association, Peru's National Institute of Health, Peru's National Institute of Statistics and Informatics, Peru's Social Security Health Service (EsSALUD), among other institutions. Whilst direct impact on policy cannot be documented, one of the most verifiable indicators is the recognition of our group by policymakers as an established research group, conducting meaningful research for the country's needs including topics such as human resources for health [54], a health system analyses of barriers to hypertension and diabetes care [55], and the exploration of the burden of disability including caregivers [56]. Because of the strong ties we have developed with various of these organizations, our Centre tends to be invited or consulted for relevant policy forums, both at the national and regional levels.

Advocacy at the local level is closely tied to policy development. In the international arena, our Centre has advocated for region-specific diabetes forecasts [57], global responses to non-communicable diseases [58-60] including criticism towards the current predominance of north-only voices in the area [61], the need for flexibility and adaptation of global health curriculum [62], and the challenges of epidemiology in the Latin American region whilst actively advocating for South-South collaborations [63, 64]. In March 2015, our Centre hosted the second Emerging Leaders Think Thank Seminar, an ongoing programme of the World Heart Federation [65], thus contributing to advancing the prominence of Latin America in contemporary global health issues.

Our Centre is also required to actively participate in external activities and interactions, some of which serve as some form of knowledge translation or knowledge transfer and citizenship. This is particularly challenging in our Peruvian context, and at the international level, for two key reasons. One relates to our ability to be an active and meaningful contributor in every single arena. The interconnectedness between chronic noncommunicable diseases with many other areas provides important opportunities to interact with many nonhealth actors at different levels, from transport to agriculture, to policy development and policy making, urban planning, and aid/development, to name a few. The other factor is the limited number of long-term interlocutors, particularly from the public sector, due to high turnover of key personnel within the system. Despite limited resources and time, we try to sustain participation in these different venues and with these different counterparts. The very same concept of building, nurturing and maintaining trustworthy relationships, as 
expressed in the case of our research collaborators, applies to our non-research partners, including policy makers and civil servants.

\section{Lessons learned: leadership, trust and time as assets towards ensuring sustainability}

Another key component of any successful partnership is to learn from its experiences and in particular to learn from its failures, a key message constantly instilled by the group's leaders. In this section we reflect and elaborate on key lessons learnt from the process of establishing a Centre of Excellence with a long-term vision. We place particular emphasis on how our Centre's structure and activities fuse to contribute to ensuring its sustainability. Two key non-monetary assets, time and trust, are carefully scrutinised below.

\section{Grant writing}

The development of our Centre did not occur in isolation of funding support, which is crucial for its expansion and sustainability. While some funding opportunities are available to us without collaboration with a high-income country institution, in many cases it is either required or adds significant strength to our applications. As a result, as shown by the co-authorship base in this manuscript, we have gradually formed strong and trusted connections with researchers in highincome countries. Trust is a crucial component of these relationships and is a key to sustainability. Establishing and maintaining trust requires a significant investment of time and energy. This nurturing process is crucial as we learn to work together and to contribute to the advancement of mutual goals in a meaningful way.

Obtaining funding is one of the greatest challenges in academic research, and is particularly difficult in the context of transitioning economies such as Peru. Our Centre has little in-country support for research, and primarily relies on research funding from larger established funding bodies in Canada, UK and USA. While available international funding previously focused on infectious diseases research that were unique to low- and middle-income countries, recent initiatives recognise the value of global investigations into non-communicable diseases. Most of the funding available for research comes from international sources including publicprivate partnerships, though some opportunities that focus on training of local researchers are also required. The latter is a major challenge for Peru's development, and has to be addressed locally.

\section{Flexibility to expand into newer research areas}

The core research group is entirely funded through research grants. Grant writing consumes a sizeable portion of our efforts, and it is crucial/essential to anticipate future periods of uncertainty. A practical limitation is that there is not always time to take away from ongoing research efforts to focus in new grant applications, which are often diverse and demands moving beyond our comfort zone. As progress in science today occurs largely at the boundaries of domains, working with multidisciplinary teams is a particular challenge, as part of our strategy for sustainability relies on expanding our portfolio of research. However, this is also positive because we constantly learn about new topics and approaches, pressing us to break down any signal of rooting into silo mentalities, as shown above in the diverse ongoing areas of partnership and collaborations. In the same vein, it hinders our capacity to specialise and reflect on the research findings as much as we would like. In practice, this scenario places us on a constant search for balance and equilibrium between risk aversion and spreading ourselves too thin. As discussed elsewhere, the Centre is not a risk-averse organisation: "it benefits from past experiences, including past mistakes, improves upon them, and challenges traditional research approaches. This ethos and environment is strategic to fostering innovation in research" [4].

\section{Investing in students and early career professionals}

Equally important is investing in younger generations, which includes securing and providing them with a meaningful and challenging space to make contributions. In this regard, part of our success in this short time can be attributed to capacity building support. As a research group, we strive to "do more" beyond answering our specific research questions, which requires that we invest our most valuable resource-time-to provide opportunities and mentorship to younger investigators to lead the preparation of manuscripts as well as grant proposals.

The flip side of the coin is that most of these ventures are not funded and require a major degree of commitment from the Centre's investigators and the individuals in training. In addition, separate time and effort are also devoted to ensure adequate communication within the CRONICAS team, not only to monitor the progress of projects, but also to hear about the individual's career development needs. Remaining actively sensitive to the career development paths of our trainees is not only about research methodology, but equally important, to develop and excel skills for cross-disciplinary and crossnational research, paired with skills to manage and develop their professional lives, as well as to ensuring that they remain engaged in their research.

\section{Dynamic interactions}

Our Centre has put in place two strategies to ensure quality interactions and provides, on a day-to-day basis, 
a meaningful and challenging space to its members, from students to full-time investigators. First, we instituted a horizontal structure, in terms of relationships and office arrangements, which facilitates the exchange of ideas, discussions, project management tips, lessons learnt, and pitfalls to avoid in the future (see Fig. 1). Such structure enables fluid unplanned interactions, minimising hierarchies, between trainees, research project staff, and the Centre's investigators. Second, we have a one-day per week open door policy for individuals or teams interested in the Centre's activities to interact freely and openly with our staff. In so doing, our
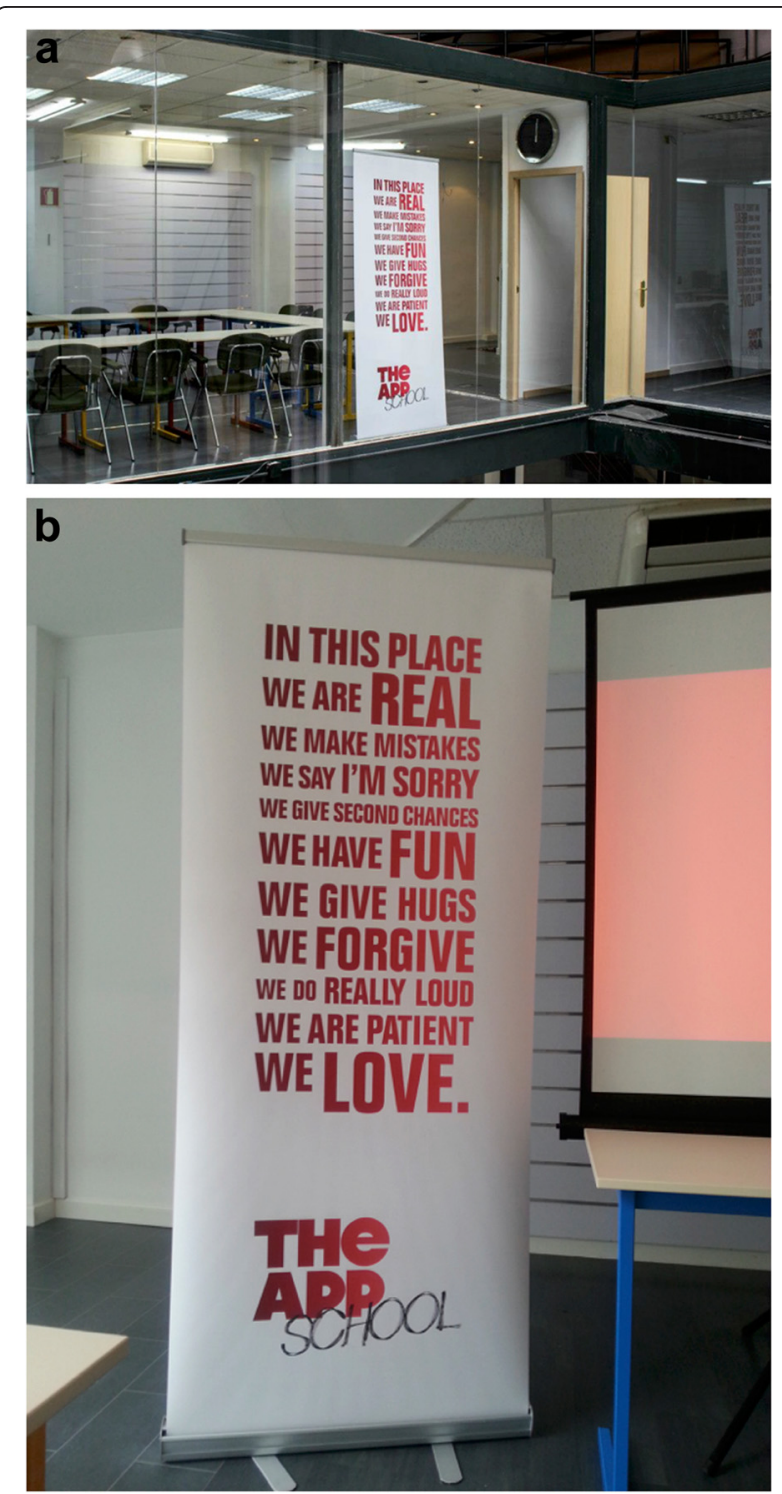

Fig. 1 Fostering horizontally driven capacity building environments. Some features that promote an environment where mutual learning and horizontality is promoted ( $\mathbf{a}$ and $\mathbf{b}$ ). Source: The App School, http://theappschool.com/ strategies affirm our Centre's values of generosity, innovation, integrity and quality.

\section{Conclusions}

The CRONICAS Centre of Excellence in Chronic Diseases at Universidad Peruana Cayetano Heredia is proud of its origins, thankful for its individual and institutional collaborators as well as its hosting environment, and appreciative of the initial funding from the National Heart, Lung and Blood Institute that enabled its creation $[4,5]$ as well as contributions from various other funding agencies. Within 5 years of its inception, the Centre has demonstrated that it is an established group, both in the Peruvian and international context.

More challenges will come, more adventures will follow, and the Centre will continue supporting the expansion of Peru's critical mass available to conduct research, inform health policy and policy decision making, advance for global health, and continue to progress under its core values of generosity, innovation, integrity and quality.

The CRONICAS Centre' experience described in this manuscript serves as an ongoing example of a Peruvianled international actor in research whose experiences and trajectory ascertains important lessons for various partnerships whilst embracing multiple stakeholders. This experience fits nicely with the proposed definition of transboundary and intercultural research in partnership as a "continuous process of sound knowledge generation, building mutual trust, mutual learning and shared ownership" [26, 27]. Many other research groups and organisations located in the global South are well positioned to evaluate their current status of relationships, to make objective claims of true partnerships, and to contribute to the promotion of a culture of global solidarity where mutual goals, mutual gains, as well as mutual responsibilities are the norm. In so doing, we will all contribute to instil a new culture of expectations, roles and interactions among individuals and their teams, the true nature of partnerships.

The Centre's presence in the Latin American region provides an additional anchor to maximize capacity building initiatives across countries. For example, the team's dynamics and experiences described in this manuscript can be used as an example, out of many available, to inform about models of partnerships where costs of collaborations can be reduced and become more efficient in terms of investments and yield.

\section{Abbreviations}

CONCYTEC, Consejo Nacional de Ciencia, Tecnología e Innovación

Tecnológica; EsSalud, Seguro Social del Perú; KFPE, Swiss Commission for Research Partnerships with Developing Countries; NAMRU-6, U.S. Naval Medical Research Unit No. 6. 


\section{Acknowledgements}

The authors are indebted to all current and previous CRONICAS staff, trainees and students that throughout the years have contributed to make what CRONICAS is today. We are also thankful to all participants who kindly agreed to participate to many of the studies conducted by the Centre. Special thanks to all field teams for their commitment and hard work, including Lilia Cabrera, Rosa Salirrosas, Viterbo Aybar, Sergio Mimbela, and David Danz for their leadership in each of the study sites, Marco Varela for data coordination, and José Alfredo Zavala for preparing the maps. Our special gratitude to Silvia Rodríguez, her early departure is a great loss to our Peruvian research network

The recognition is extended to our wider list of collaborators that have contributed, in several meaningful ways, with suggestions, ideas and shared thoughts for best possible research studies. This includes, in a nonexhaustive list, Adrián Alasino, Nöel Barengo, Camila Corvalán, George Davey Smith, Shah Ebrahim, Majid Ezzati, Harold I Feldman, David Gordon, Pedro Hallal, John N Lavis, Homero Martínez, Paulo Menezes, Shailen Nandy, Vikram Patel, Michael Pratt, Miguel Pinto, Manuel Ramirez-Zea, Adolfo Rubinstein, Ricardo Uauy, Alberto Vásquez, Cesar G Victora, and John S Yudkin.

\section{Funding}

The establishment of the CRONICAS Centre of Excellence in Chronic Diseases at Universidad Peruana Cayetano Heredia was funded in whole with Federal funds from the National Heart, Lung and Blood Institute, National Institutes of Health, Department of Health and Human Services, under Contract No. HHSN268200900033C.

The support of several institutions, listed in alphabetical order, is credited: Alliance for Health Policy and Systems Research (HQHSR1206660), Consejo Nacional de Ciencia, Tecnología e Innovación Tecnológica (CONCYTEC), DFID/MRC/Wellcome Global Health Trials (MR/M007405/1), Fogarty International Center (R21TW009982), Grand Challenges Canada (0335-04), International Development Research Center Canada (106887, 108167), InterAmerican Institute for Global Change Research (IAI CRN3036), Medtronics Philanthropy, National Heart, Lung and Blood Institute (5U01HL114180, HHSN268200900028C), National Institute of Mental Health (1U19MH098780), Swiss National Science Foundation (40P740-160366), UnitedHealth Foundation, Universidad Peruana Cayetano Heredia, Wellcome Trust (GR074833MA, WT093541AIA, 103994/Z/14/Z), and World Bank.

Ricardo Araya declares receiving funding from the Wellcome Trust, National Mental Health Institute, Grand Challenges Canada, and United Kingdom's Medical Research Council. Antonio Bernabé-Ortiz is supported by Wellcome Trust through a Research Training Fellowship (103994/Z/14/Z). William Checkley was supported by a Pathway to Independence Award (R0OHL096955) from the National Heart, Lung and Blood Institute. The Global Health Peru Program - UPCH was funded by Fogarty International Center (R25TW00490). Participation of Andrés G Lescano and the UPCH/NAMRU-6 Epidemiology Masters were funded by the program "Peruvian Consortium of Training in Infectious Diseases" awarded by the Fogarty International Center (2D43 TW000393). David C. Mohr receives funding from the United States National Institute of Mental Health grants P20-MH09031, R01-MH095753, R01-MH100482, R34-MH095907. Liam Smeeth is a Senior Clinical Fellow and Héctor H García a Senior Fellow in Public Health and Tropical Medicine, both funded by Wellcome Trust. The funders had no role in decision to publish, or preparation of the manuscript.

\section{Availability of data and materials}

Not applicable.

\section{Authors' contributions}

JJM conceived the manuscript and wrote the first draft. All authors participated in writing of manuscript, contributed to specific sections, provided important intellectual input and content, and gave their final approval of the version submitted for publication.

\section{Competing interests}

The authors declare that they have no competing interests.

\section{Consent for publication}

Not applicable.
Ethics approval and consent to participate

Not applicable.

\section{Disclaimer}

The views expressed in this article are those of the authors only and do not necessarily reflect the official policy or position of the Department of the Navy, Department of Defense, Department of Health \& Human Services, nor the U.S. Government.

\section{Copyright statement}

One author of this manuscript is an employee of the U.S. Government. This work was prepared as part of his duties. Title 17 U.S.C. 1105 provides that 'Copyright protection under this title is not available for any work of the United States Government.' Title 17 U.S.C. 1101 defines a U.S. Government work as a work prepared by a military service member or employee of the U.S. Government as part of that person's official duties.

\section{Author details}

${ }^{1}$ CRONICAS Centre of Excellence in Chronic Diseases, Universidad Peruana Cayetano Heredia, Av. Armendáriz 497, Miraflores, Lima 18, Peru. ${ }^{2}$ School of Medicine, Universidad Peruana Cayetano Heredia, Lima, Peru. ${ }^{3}$ School of Public Health and Administration, Universidad Peruana Cayetano Heredia, Lima, Peru. ${ }^{4}$ Division of Internal Medicine, Hospital Nacional Cayetano Heredia, Lima, Peru. ${ }^{5}$ Faculty of Epidemiology and Population Health, London School of Hygiene and Tropical Medicine, London, UK. ${ }^{6}$ Division of Tropical and Humanitarian Medicine, Geneva University Hospitals, Geneva, Switzerland. ${ }^{7}$ University of Geneva, Geneva, Switzerland. ${ }^{8}$ Instituto de Estudios Peruanos, Lima, Peru. 'Division of Non-Communicable Diseases, Dirección General de Salud de las Personas, Ministerio de Salud, Lima, Peru. ${ }^{10}$ Division of Pulmonary and Critical Care, School of Medicine, Johns Hopkins University, Baltimore, MD, USA. ${ }^{11}$ Department of International Health, Johns Hopkins Bloomberg School of Public Health, Baltimore, MD, USA.

${ }^{12}$ Department of Pediatrics, Instituto Nacional de Salud del Niño, Lima, Peru.

${ }^{13}$ School of Medicine, Universidad Nacional Mayor de San Marcos, Lima, Peru.

${ }^{14}$ School of Sciences, Universidad Peruana Cayetano Heredia, Lima, Peru.

${ }^{15}$ Department of Parasitology, and Public Health Training Program, USA Naval Medical Research Unit No. 6 (NAMRU-6), Lima, Peru. ${ }^{16}$ Center for Behavioral Intervention Technologies, Feinberg School of Medicine, Northwestern University, Chicago, IL, USA. ${ }^{17}$ Division of Environmental Science and Policy, Nicholas School of the Environment, Duke University, Durham, NC, USA. ${ }^{18}$ The George Institute for Global Health, University of Sydney, Sydney, New South Wales, Australia. ${ }^{19}$ World Heart Federation, Geneva, Switzerland. ${ }^{20}$ Office of Global Affairs, U.S. Department of Health \& Human Services, Washington, DC, USA. ${ }^{21}$ Childhood Nutrition Research Centre, UCL Institute of Child Health, University College London, London, UK. ${ }^{22}$ Global Health Research Center, Duke Kunshan University, Kunshan, Jiangsu, China. ${ }^{23}$ Center for Global Health - Tumbes, Universidad Peruana Cayetano Heredia, Tumbes, Peru. ${ }^{24}$ Cysticercosis Unit, Instituto Nacional de Ciencias Neurológicas, Lima, Peru. ${ }^{25}$ Asociación Benéfica PRISMA, Lima, Peru.

Received: 30 June 2015 Accepted: 18 May 2016

Published online: 02 June 2016

\section{References}

1. Bloom DE, Cafiero ET, Jané-Llopis E, Abrahams-Gessel S, Bloom LR, Fathima S, Feigl AB, Gaziano T, Mowafi M, Pandya A, Prettner K, Rosenberg $L$, Seligman B, Stein A, Weinstein C. The Global Economic Burden of Noncommunicable Diseases. Geneva: World Economic Forum; 2011.

2. World Health Organization. Noncommunicable diseases country profiles 2014. Geneva: World Health Organization; 2014.

3. World Health Organization. Global action plan for the prevention and control of noncommunicable diseases 2013-2020. Geneva: World Health Organization; 2013.

4. Miranda JJ, Bernabe-Ortiz A, Diez-Canseco F, et al. Building a platform for translational research in chronic noncommunicable diseases to address population health: lessons from NHLBI supported CRONICAS in Peru. Glob Heart. 2015;10:13-9.

5. Engelgau MM, Sampson UK, Rabadan-Diehl C, et al. Tackling NCD in LMIC: achievements and lessons learned from the NHLBI-UnitedHealth Global Health Centers of Excellence Program. Glob Heart. 2016;11:5-15. 
6. Hill L, Fernández-Aráoz C. The Future of Talent is Potential. Harvard Business Review; 2014 [updated 2014; cited 201530 Jun]; Available from: https://hbr. org/2014/07/the-future-of-talent-is-potential/.

7. Gotuzzo E, Gonzalez E, Verdonck K. Researchers training in the context of the collaborative projects: experiences of Instituto de Medicina Tropical "Alexander von Humbolt", Universidad Peruana Cayetano Heredia. Revista peruana de medicina experimental y salud publica. 2010;27:419-27.

8. Garcia PJ, Curioso WH. Strategies for aspiring biomedical researchers in resource-limited environments. PLoS Negl Trop Dis. 2008;2:e274

9. Guerra H. Return scholarship of the Universidad Peruana Cayetano Heredia. Revista peruana de medicina experimental y salud publica. 2010;27:428-31.

10. Gonzales GF, Guerra-Garcia R. Excellence research in altitude: fifty years after the foundation of the Instituto de Investigaciones de la altura of the Universidad Peruana Cayetano Heredia. Revista peruana de medicina experimental y salud publica. 2011;28:689-90.

11. Garcia PJ, Curioso WH, Lazo-Escalante M, et al. Global health training is not only a developed-country duty. J Public Health Policy. 2009;30:250-2.

12. Freedman DO, Gotuzzo E, Seas C, et al. Educational programs to enhance medical expertise in tropical diseases: the Gorgas Course experience 19962001. Am J Trop Med Hyg. 2002;66:526-32.

13. Consejo Nacional de Ciencia Tecnología e Innovación Tecnológica. Principales indicadores bibliométricos de la actividad científica peruana: 2006-2011. Lima: CONCYTEC. Available at: http://dspace.concytec.gob.pe/ handle/concytec/96.

14. Bloomfield GS, Xavier D, Belis D, et al. Training and capacity building in LMIC for Research in Heart and Lung Diseases: the NHLBI-UnitedHealth Global Health Centers of Excellence Program. Glob Heart. 2016;11:17-25.

15. Dowling B, Powell M, Glendinning C. Conceptualising successful partnerships. Health Soc Care Community. 2004;12:309-17.

16. Lasker RD, Weiss ES, Miller R. Partnership synergy: a practical framework fo studying and strengthening the collaborative advantage. Milbank Q. 2001; 79:179-205. III-IV.

17. World Bank. Poverty \& Equity. Peru: Country Dashboard; 2015. [updated 2015; cited 201530 Jun], Available from: http://povertydata.worldbank.org/ poverty/country/PER

18. Dmytraczenko T, Almeida G. Toward Universal Health Coverage and Equity in Latin America and the Caribbean. Evidence from Selected Countries. Washington, DC: World Bank, Pan American Health Organization; 2015.

19. World Bank. Data: Health Expenditure per Capita. World Bank; 2014 [updated 2014; cited 201530 Jun]; Available from: http://data.worldbank. org/indicator/SH.XPD.PCAP.

20. OECD. Better Policies for Better Lives. Peru Student Performance (PISA 2012). 2012 [updated 2012; cited 201530 Jun]; Available from: http://gpseducation. oecd.org/CountryProfile?primaryCountry=PER.

21. Coloma J, Harris E. From construction workers to architects: developing scientific research capacity in low-income countries. PLoS Biol. 2009;7:e1000156.

22. Lau CY, Wang C, Orsega S, et al. International Collaborative Research Partnerships: Blending Science with Management and Diplomacy. J AIDS Clin Res. 2014;5:385. http://www.omicsonline.org/open-access/internationalcollaborative-research-partnerships-blending-science-with-managementand-diplomacy-2155-6113.1000385.pdf.

23. Pratt B, Loff B. Linking research to global health equity: the contribution of product development partnerships to access to medicines and research capacity building. Am J Public Health. 2013;103:1968-78.

24. Adewole I, Martin DN, Williams MJ, et al. Building capacity for sustainable research programmes for cancer in Africa. Nat Rev Clin Oncol. 2014;11:251-9.

25. Sharma A, Chiliade P, Michael Reyes $E$, et al. Building sustainable organizational capacity to deliver HIV programs in resource-constrained settings: stakeholder perspectives. Glob Health Action. 2013;6:22571.

26. Stöckli B, Wiesmann U, Lys J-A. A Guide for Transboundary Research Partnerships: 11 Principles. Bern, Switzerland: Swiss Commission for Research Partnerships with Developing Countries (KFPE); 2014.

27. Wiesmann U, Stöckli B, Lys J-A. A Guide for Transboundary Research Partnerships: 7 Questions. Bern, Switzerland: Swiss Commission for Research Partnerships with Developing Countries (KFPE); 2014.

28. SCImago Institutions Rankings. SIR Methodology. SCImago Research Group; [cited 2016 May 2]; Available from: http://www.scimagoir.com/ methodology.php.

29. Garcia P, Armstrong R, Zaman MH. Models of education in medicine, public health, and engineering. Science. 2014;345:1281-3.
30. Frenk J, Chen L, Bhutta ZA, et al. Health professionals for a new century: transforming education to strengthen health systems in an interdependent world. Lancet. 2010;376:1923-58.

31. Poterico JA, Stanojevic S, Ruiz-Grosso P, et al. The association between socioeconomic status and obesity in Peruvian women. Obesity (Silver Spring). 2012;20:2283-9.

32. Carrillo-Larco RM, Bernabe-Ortiz A, Miranda JJ, et al. Peruvians' sleep duration: analysis of a population-based survey on adolescents and adults. PeerJ. 2014;2:e345.

33. Burroughs Pena MS, Bernabe-Ortiz A, Carrillo-Larco RM, et al. Migration, urbanisation and mortality: 5-year longitudinal analysis of the PERU MIGRANT study. J Epidemiol Community Health. 2015;69:715-8.

34. CRONICAS Centro de Excelencia en Enfermedades Crónicas, Universidad Peruana Cayetano Heredia. CRONICAS Trainee's publications [Online]. Bethesda, MD: National Center for Biotechnology Information, U.S. National Library of Medicine; [cited 2014 2014-08-15]; Available from: http://www. ncbi.nlm.nih.gov/myncbi/browse/collection/40575995.

35. Sterling R, Miranda JJ, Gilman RH, et al. Early anthropometric indices predict short stature and overweight status in a cohort of Peruvians in early adolescence. Am J Phys Anthropol. 2012;148:451-61.

36. Miranda JJ, Davies AR, Smith GD, et al. Frequency of diarrhoea as a predictor of elevated blood pressure in children. J Hypertens. 2009;27:259-65.

37. Sterling R, Checkley W, Gilman RH, et al. Beyond birth-weight: early growth and adolescent blood pressure in a Peruvian population. PeerJ. 2014;2:e381.

38. Batty GD, Victora CG, Lawlor DA. Establishing family-based life course studies in low- and middle-income countries. In: Lawlor DA, Mishra GD, editors. Family matters: designing, analysing and understanding family based studies in life course epidemiology. Oxford: Oxford University Press; 2009. p. 129-50.

39. Ebrahim S, Pearce N, Smeeth L, et al. Tackling non-communicable diseases in low- and middle-income countries: is the evidence from high-income countries all we need? PLoS Med. 2013;10:e1001377.

40. Niermeyer S, Andrade Mollinedo P, Huicho L. Child health and living at high altitude. Arch Dis Child. 2009;94:806-11.

41. Rivera-Ch M, Leon-Velarde F, Huicho L. Treatment of chronic mountain sickness: critical reappraisal of an old problem. Respir Physiol Neurobiol. 2007;158:251-65.

42. Rivera-Ch M, Castillo A, Huicho L. Hypoxia and other environmental factors at high altitude. Int J Environ Health. 2008;2:92-106.

43. De Ferrari A, Miranda JJ, Gilman RH, et al. Prevalence, clinical profile, iron status and subject-specific traits for excessive erythrocytosis in Andean adults living permanently at 3825 meters above sea level. Chest. 2014;146: 1327-36.

44. Painschab MS, Malpartida GE, Davila-Roman VG, et al. Association between serum concentrations of hypoxia inducible factor responsive proteins and excessive Erythrocytosis in high altitude Peru. High Alt Med Biol. 2015;16: 26-33.

45. Vyas KJ, Danz D, Gilman RH, et al. Noninvasive assessment of excessive Erythrocytosis as a screening method for chronic mountain sickness at high altitude. High Alt Med Biol. 2015;16:162-8.

46. Hooper-Miele CC, Pham L, Schwartz AR, et al. A Connection Between Chronic Daytime Hypoxia and Metabolic Syndrome: Identifying Patterns of Cardiovascular Risk Factors at High Altitude. B29. RESPIRATORY MUSCLE AT WORK: IS IT 'ALL ABOUT THAT BASS'?: American Thoracic Society; 2015. p. A2667-A. Available at: http://www.atsjournals.org/doi/abs/10.1164/ajrccm-conference.2015.191.1 MeetingAbstracts.A2667.

47. Wells JC, Chomtho S, Fewtrell MS. Programming of body composition by early growth and nutrition. Proc Nutr Soc. 2007;66:423-34.

48. Pomeroy E, Stock JT, Stanojevic S, et al. Trade-offs in relative limb length among Peruvian children: extending the thrifty phenotype hypothesis to limb proportions. PLOS ONE. 2012;7:e51795.

49. Pomeroy E, Stock JT, Stanojevic S, et al. Associations between arterial oxygen saturation, body size and limb measurements among high-altitude Andean children. Am J Hum Biol. 2013;25:629-36.

50. Pomeroy E, Stock JT, Stanojevic S, et al. Stunting, adiposity, and the individual-level "dual burden" among urban lowland and rural highland Peruvian children. Am J Hum Biol. 2014;26:481-90.

51. Pomeroy E, Wells JC, Stanojevic S, et al. Surname-Inferred andean ancestry is associated with child stature and limb lengths at high altitude in Peru, but not at sea level. Am J Hum Biol. 2015. 
52. Danysh HE, Gilman RH, Wells JC, et al. El Niño adversely affected childhood stature and lean mass in northern Peru. Climate Change Responses. 2014;1:7.

53. Bennett A, Epstein LD, Gilman RH, et al. Effects of the 1997-1998 El Nino episode on community rates of diarrhea. Am J Public Health. 2012;102:e63-9.

54. Jiménez MM, Mantilla E, Huayanay-Ezpinoza CA, et al. Demand for training and availability of health science professionals in Peru. Revista peruana de medicina experimental y salud publica. 2015;32:41-50.

55. Cárdenas MK, Morán D, Beran D, et al. Identifying the Barriers for Access to Care and Treatment for Arterial Hypertension and Diabetes in Lima, Peru. Lima: CRONICAS Centro de Excelencia en Enfermedades Crónicas, Universidad Peruana Cayetano Heredia; 2014.

56. Bernabe-Ortiz A, Diez-Canseco F, Vasquez A, et al. Disability, caregiver's dependency and patterns of access to rehabilitation care: results from a national representative study in Peru. Disabil Rehabil (in press).

57. Pillay TD, Bernabe-Ortiz A, Malaga G, et al. Should rural Latin America align to the international diabetes rise forecasts? Diabetes Res Clin Pract. 2012;97:e1-2.

58. UnitedHealth Group, National Heart Lung Blood Institute Centers of Excellence, Cerqueira MT, et al. Global response to non-communicable disease. BMJ. 2011;342:d3823.

59. UnitedHealth Group/National Heart L, Blood Institute Centres of E. A global research network for non-communicable diseases. Lancet. 2014;383:1446-7.

60. Pearce N, Ebrahim S, McKee M, et al. The road to 25×25: How can the fivetarget strategy reach its goal? Lancet Global Health. 2014;2:e126-8.

61. Carrillo-Larco RM, Demaio AR, Miranda JJ. Addressing NCDs: is it really a global coalition? Lancet. 2013;381:2081. discussion -2.

62. Rowson M, Willott C, Hughes $\mathrm{R}$, et al. Conceptualising global health theoretical issues and their relevance for teaching. Global Health. 2012;8:36.

63. Miranda JJ, Garcia PJ, Lescano AG, et al. Global Health Training-One Way Street? Am J Trop Med Hyg. 2011;84:506.

64. Barreto SM, Miranda JJ, Figueroa JP, et al. Epidemiology in Latin America and the Caribbean: current situation and challenges. Int J Epidemiol. 2012; 41:557-71.

65. Huffman MD, Labarthe DR, Yusuf S. Global cardiovascular research training for implementation science, health systems research, and health policy research. J Am Coll Cardiol. 2015;65:1371-2.

\section{Submit your next manuscript to BioMed Central and we will help you at every step:}

- We accept pre-submission inquiries

- Our selector tool helps you to find the most relevant journal

- We provide round the clock customer support

- Convenient online submission

- Thorough peer review

- Inclusion in PubMed and all major indexing services

- Maximum visibility for your research

Submit your manuscript at www.biomedcentral.com/submit

) Biomed Central 